\title{
Internationalising in small, incremental or larger steps?
}

\author{
Harry G Barkema ${ }^{1,2,3}$ and \\ Rian Drogendijk ${ }^{4}$
}

${ }^{1}$ Department of Organisation and Strategy, Tilburg University, Tilburg, The Netherlands; ${ }^{2}$ Department of Management, London School of Economics, London, UK; ${ }^{3}$ Department of Technology and Innovation Management, Rotterdam School of Management, Rotterdam, The Netherlands; ${ }^{4}$ Department of Business Studies, Uppsala University, Uppsala, Sweden

Correspondence:

H Barkema, Tilburg University, PO Box 90153, 5000 LE Tilburg, The Netherlands. Tel: + 3113466 2243;

Fax: + 3113466 8354;

E-mail: barkema@uvt.nl
Received: 10 November 2005

Revised: 11 October 2006

Accepted: 19 June 2007

Online publication date: 6 September 2007

\begin{abstract}
We argue that companies may enter foreign environments either incrementally, as suggested by long-established theory, or by taking larger steps that may result in lower initial performance but, through learning and experience, lead to increased performance in future expansions. This idea is corroborated by the experience of Dutch companies entering into Central and Eastern Europe. We also find that expansion steps may be too large, thereby limiting the exploration of foreign environments. Our study suggests that sequential internationalisation strategies do still matter, and that companies have to balance exploitation and exploration in internationalisation.

Journal of International Business Studies (2007), doi: I 0. I057/palgrave.jibs.84003I5
\end{abstract}

Keywords: internationalisation; learning; cultural differences; exploitation and exploration

\section{Introduction}

A key theme of the 2005 JIBS Emerging Frontiers Conference was: Does the internationalisation process still matter? Internationalisation process models have existed since the early days of IB (Aharoni, 1966; Root, 1987). The well-known Uppsala model (Johanson and Vahlne, 1977, 1990) suggests that companies internationalise in small, incremental steps, as risk-averse managers recognise and seize expansion opportunities in their local foreign environments (cf. Cyert and March, 1963). This model was inspired by the internationalisation patterns of the 1970s and earlier, when companies entered neighbouring countries by first using sales agents and then making direct investments (Johanson and Wiedersheim-Paul, 1975; Johanson and Mattson, 1985). In retrospect, this research was surprisingly modern in conceptualising the expansion of firms as a sequential, path-dependent learning process.

However, the world has changed in several ways. Firms are less inclined to repeat the value chain in each country, reconfiguring it instead globally in terms of where revenues are high or costs are low. Companies in many industries are now racing to internationalise, entering regions such as South-East Asia, Latin America, and Central and Eastern Europe (CEE) (Knickerbocker, 1973; Hitt et al., 1998). Seeking to become global players in their industries, they try to internationalise and learn faster than their competitors (Barkema et al., 2002; Doz et al., 2001), with FDI in developing regions accumulating to $\$ 233$ billion in $2004,36 \%$ of the total (UNCTAD, 2005). Companies that are too risk-averse may win the 
battle (i.e., develop a successful expansion) but lose the war (i.e., the learning race for global dominance). Instead, a trade-off may be needed between short-term gains through successful expansions and long-term benefits through learning from expansions to build future success.

To address these new realities, we offer a new perspective while retaining some important notions of the Uppsala model. We argue that companies may emphasise either exploitation of their knowledge of foreign environments - and particularly of national cultures - or exploration. Exploitation emphasises refinement of the company's existing knowledge base through incremental steps, reducing the risks of foreign expansion, as in the Uppsala model. Exploration is more strategic in nature. It emphasises planned variation and search, is characterised by a greater departure from the company's knowledge base (Gavetti and Levinthal, 2000), and implies more risk of current expansions, but also learning to increase the performance of future expansions (March, 1991). An exploration strategy is particularly relevant for firms engaged in a race (March, 1991). Prior research has focused the exploitation/exploration lens on the development of new technologies (Rosenkopf and Nerkar, 2001), on new businesses (McGrath, 2001), on new products (Katila and Ahuja, 2002; Holmqvist, 2004; Rothaermel and Deeds, 2004), on newly established companies (Baum et al., 2000; Winter and Szulanski, 2001), and on the issue of whether or not firms should establish separate units specialising in exploitation or exploration (Siggelkow and Levinthal, 2003; He and Wong, 2004). We applied this perspective to internationalising firms in terms of exploitation $v s$ exploration of foreign cultural environments.

We examined companies entering a new 'cultural bloc' (Ronen and Shenkar, 1985), and in particular CEE, as an example of an exploratory move. Cultural blocs - groups of countries sharing a similar culture (Ronen and Shenkar, 1985), such as South-East Asia, Latin America, CEE, and Latin Europe - have become an important unit of analysis in IB (Anderson and Gatignon, 1986; Barkema et al., 1996; Delios and Henisz, 2003; Shenkar, 2004). Cultural blocs are also important in practice, because companies often use one country as a test market before moving on to the next (Hitt et al., 1998). Regions, rather than countries, increasingly serve as a basis of competition (Buckley and Ghauri, 2004). How to learn to operate in new regions or new cultural blocs is therefore a particularly relevant issue.
We shall first develop some hypotheses that are quite similar to the Uppsala model about exploiting knowledge within a given cultural bloc, using first contractual modes (sales agents, franchising, or licensing), and then FDI. These hypotheses serve as a baseline for developing more novel hypotheses about how this incremental entry strategy compares with entering through FDI directly, in terms of short-term performance and learning. We subsequently develop theory on the exploratory move of entering a new cultural bloc. We tested our hypotheses with survey data on Dutch firms entering CEE, using factor analysis and OLS. CEE has opened up fairly recently (since 1989), and so enabled us to study learning from relatively recent entry sequences. The Netherlands is the sixth largest foreign investor worldwide, and the fifth largest foreign investor in CEE.

Our study suggests that internationalisation processes still matter, perhaps increasingly so, as learning races increasingly become a basis for global competition. Hence we address head on the emerging debate on whether internationalisation process models still matter.

\section{Background: internationalisation as a learning process}

Internationalisation process research initiated in the 1960s and 1970s was anchored in observations that companies internationalised in an incremental fashion, expanding in nearby countries in terms of culture, institutions, educational level, and language, first through sales agents, and then through FDI (sales or production subsidiaries: Aharoni, 1966; Johanson and Wiedersheim-Paul, 1975; Root, 1987). Johanson and Vahlne (1977) interpreted these observations in terms of behavioural theory, arguing that a company's foreign employees recognised and seized on new expansion opportunities in their neighbourhood (cf. Cyert and March, 1963). Managers with experiential knowledge about the environment evaluated problems and opportunities, enabling their company to expand (cf. Penrose, 1959). Together with the assumption that managers constrain the risk exposure of their companies, this led to the prediction of incremental internationalisation patterns (Johanson and Vahlne, 1977, 1990).

Empirical studies in the 1970s and 1980s corroborated the predicted incremental pattern (Buckley et al., 1978; Engwall and Wallenstål, 1988), although companies sometimes skipped the intermediate steps in the more advanced stages of internationalisation 
(Hedlund and Kverneland, 1983; Johanson and Vahlne, 1990), or entered regions further from the home market without experience in regions closer by (Benito and Gripsrud, 1992).

Later research corroborated the idea that companies adopting incremental expansion paths learned from their experience and reduced the failure rate of their investments (Li, 1995; Barkema et al., 1996; Shaver et al., 1997). However, recent evidence suggests that incremental expansion patterns, while reducing the failure rate of expansions, may not increase the company's overall profitability (Delios and Beamish, 2001). In other words, incremental expansion patterns and the lower risk of individual expansions may not always be good or optimal for a company.

\section{Theory}

A key assumption of our study is that learning how to handle foreign cultures is a necessary condition for successfully operating abroad. Since the early days of IB, researchers have emphasised the 'liability of foreignness' (Hymer, 1975), implying that a lack of knowledge of local cultures and institutions reduces performance and increases the failure rate of foreign expansions. In order to enhance the success of their foreign operations, companies need to learn about the institutions - both formal and, in particular, informal - that define how people act and interact in the new environment. Formal institutions include laws and written conventions; informal institutions comprise codes of conduct, norms, values, and behavioural conventions, together labelled 'culture' (North, 1990).

Culture has been defined as the 'programming of the mind' (Hofstede, 1980). It underlies and permeates a company's organisational structure, systems and processes (Greenwood and Hinings, 1993) as well as a country's rules, regulations and institutions. It therefore remains an important factor in studies of the strategies of multinational companies (Buckley and Ghauri, 2004; Shenkar, 2004). Many empirical studies have shown that cultural differences between home and host countries increase the hazard rate of foreign investments (Li, 1995; Barkema et al., 1996; Shaver et al., 1997). Other evidence suggests that these effects have not significantly decreased over recent decades (Barkema and Vermeulen, 1997).

\section{Cultural blocs}

Ronen and Shenkar (1985) identified cultural blocs based on eight earlier studies of culture. Countries within cultural blocs show less variance in culture than countries of different blocs. Examples of cultural blocs are: South-East Asia; Latin America; the Anglo-Saxon countries (the United States, Canada, the United Kingdom and Australia); the Nordic countries (the Netherlands, Sweden, Norway and Denmark); and the Germanic countries (Germany and Austria; Ronen and Shenkar, 1985). Several researchers have used cultural blocs as the unit of analysis, and have provided further support for the validity of measures based on cultural blocs (Anderson and Gatignon, 1986; Barkema et al., 1996; Delios and Henisz, 2003).

It has been argued that cultural blocs or regions capture important competitive conditions (Barkema et al., 2002; Buckley and Ghauri, 2004; Rugman and Verbeke, 2004). With the emergence of new markets across the globe, companies in many industries - such as the automotive industry, banking, and retailing - are increasingly racing for leadership in regions or blocs worldwide. Unlike the situation in the 1970s, when companies tended to repeat the value chain in adjacent countries (Johanson and Vahlne, 1977), regions rather than countries have become the basis of competition (Buckley and Ghauri, 2004). Nevertheless, contrary to the popular belief that the world is becoming one global village (Levitt, 1983), few companies, even among the Fortune Top 500, have become truly global companies, with major operations in Europe, the US, and Asia (Rugman and Verbeke, 2004). The combined theory and evidence suggests that entering a new cultural bloc is fraught with problems, and that expansions will likely suffer from a liability of foreignness (Hymer, 1975), especially when the cultural bloc is not a neighbouring one - for instance when a US firm enters South-East Asia.

Ronen and Shenkar (1985) did not identify CEE as a separate bloc, because CEE countries had not been studied by the culture researchers they based their study on. Although the countries in this region show differences in dominant languages, religions and ethnicity, the grouping of the CEE countries is grounded in a shared recent history of experience with a communist regime and the liberation therefrom. The communist heritage has had a far-reaching impact on the formal and cultural institutions (North, 1990) in these countries, and is visible in distinct cultural traits such as a lack of initiative taking and risk aversion among CEE managers (Luthans et al., 2000; Makhija and Stewart, 2002). In addition to the joint experience of socialism, the 
transition process towards market economic systems implied similar cultural experiences throughout the region (Peng and Heath, 1996). Feichtinger and Fink (1998) even refer to the process of sudden cultural change after 1989 as a 'collective culture shock'. Hence 'socialism has created a distinct "bloc culture"' (Meyer and Peng, 2005: 611), and 'there are a number of compelling reasons that we can consider them as one group of countries' (Peng and Heath, 1996: 494).

As a result, Western companies investing in CEE after 1989 needed to learn how to deal with common issues in these countries, related to market liberalisation, political democratisation and processes of social and cultural change, implying similar 'liabilities of foreignness' and solutions for how to handle them (for instance using 'brownfield' entry strategies; Meyer and Estrin, 2001). Hence it is not surprising that CEE countries are often treated as one bloc, both by institutions such as UNCTAD, the International Monetary Fund and the European Bank for Reconstruction and Development, and by researchers, including the authors of papers in JIBS (Meyer, 2001; Meyer and Estrin, 2001; Makhija and Stewart, 2002; Uhlenbruck, 2004; Meyer and Peng, 2005; Wooster, 2006).

\section{Exploitation vs exploration}

We define a company's knowledge base of foreign cultures as its rules, procedures, conventions and strategies for how to operate in foreign cultures, as well as the underlying structure of knowledge and beliefs (Levitt and March, 1988; Greenwood and Hinings, 1993). Organisational learning about foreign cultures means that companies expand their knowledge base in this domain, including their routines (Levitt and March, 1988; Zollo and Winter, 2002) and their knowledge and belief structures (Cohen and Levinthal, 1990; Walsh, 1995). Companies can learn through exploitation or exploration.

Earlier, in a technological context, exploitation has been defined as improving on existing components, technological trajectories (Benner and Tushman, 2002) or product-market domains (He and Wong, 2004), whereas exploration has been defined as a shift to a different technological trajectory (Benner and Tushman, 2002) or as entering a new product-market domain (He and Wong, 2004; see also Jansen et al., 2006, and Sidhu et al., 2007). We shall apply these concepts to the international domain, and argue that they can be applied to expansions within an existing cultural bloc, as opposed to entering a new cultural bloc.

\section{Exploitation}

Companies tend to search for solutions in the neighbourhood of current practices and routines (Cyert and March, 1963). This pattern has been observed in many fields, including R\&D spending (Helfat, 1994), product design (Martin et al., 1998), patenting activity (Stuart and Podolny, 1996), and strategy (Lei et al., 1996). In the international domain, Johanson and Vahlne (1977) argued that local managers' experiential knowledge influences which business opportunities companies are aware of, and expansions are the result of local search. The more committed to a market companies are, and the more knowledge they have, the larger the 'opportunity horizon' and the lower their uncertainty, enabling them to expand the company. Many researchers examining data up to the 1970 s and 1980s observed the resulting incremental expansion pattern (Buckley et al., 1978; Engwall and Wallenstål, 1988; Hedlund and Kverneland, 1983). This is consistent with other research showing that companies seize opportunities that are close to their operations in space and time (Levinthal and March, 1993; Baum et al., 2000).

When expanding in the neighbourhood of their knowledge base of foreign cultures, companies improve and refine their existing knowledge. This may lead to the semi-automatic reproduction of their routines (Zollo and Winter, 2002; Ahuja and Lampert, 2001), and to the application of existing concepts and objects and the linkages between them, rather than to the development of new ones (Cohen and Levinthal, 1990). This is consistent with a strategy of exploitation (March, 1991), implying low risk and a focus on short-term performance. Companies follow a strategy of exploitation when, having entered a cultural bloc, they expand to other countries in the same bloc with similar cultures (Ronen and Shenkar, 1985), refining their knowledge and routines about cultures. They also follow a strategy of exploitation when they commit to new markets incrementally, first using low-commitment modes such as sales agents, before moving on to direct investments, consistent with the predictions of the Uppsala model (Johanson and Vahlne, 1977).

\section{Exploration}

Companies may adopt a different strategy. They may search for and identify expansion opportunities in cultural environments further away, using staff at $\mathrm{HQ}$, external consultants, or the Internet. These may be market-seeking or resource-seeking 
opportunities (Johanson and Vahlne, 1977; Vernon, 1966), opportunities to play 'global chess' (Hout et al., 1982) or to tap into distant market or technological knowledge (Barkema and Vermeulen, 1998; Doz et al., 2001), all of which require then to learn how to handle local cultures to reduce the liability of foreignness (Hymer, 1975). Foreign environments that are new to companies and differ from those previously experienced represent new opportunities for learning, and cause companies to shift from an unconscious, routine mode of behaviour towards more active thinking (Louis and Sutton, 1991), stimulating the assimilation of new information and prompting its creative and productive use (Cohen and Levinthal, 1990).

Exploration is learning through processes of planned variation or experimentation, and is more uncertain in terms of outcomes (Baum et al., 2000). Such 'long jumps' in time and space from the company's knowledge base (Levinthal, 1997; Gavetti and Levinthal, 2000) reduce short-term performance but enhance learning and the performance of future expansions.

Entering a new cultural bloc is an exploratory move. It implies entering a distinct group of countries that are relatively homogeneous in terms of culture. For instance, Hofstede and Bond (1988), when seeking to replicate Hofstede's research (based on IBM subsidiaries in the 1970s and earlier) in Asia, found that a new concept was needed to characterise the fundamental dimensions of this culture: long-term orientation. People in societies scoring high on this variable (China has the highest score) know many truths and prefer to invest for the long run, in contrast to people in societies with low scores, who tend to believe in one absolute truth and expect quick results (Hofstede and Bond, 1988). People from these different societies have different objectives and perceive different opportunities and threats (Schneider and De Meyer, 1991): for instance, one business partner may feel a sense of urgency and seek quick results, whereas the other takes a long-term view and favours investing in financial assets and building up a relationship with the partner. This difference is likely to breed misunderstanding and tensions (Barkema and Vermeulen, 1997). It is difficult for Westerners to understand these differences in time horizon, yet understanding and handling them is essential for success (Beamish and Wang, 1989). Hence companies entering new cultural blocs may need to learn very different concepts, how these relate to other concepts, and how this learning translates into strategies, rules, procedures and conventions that are effective in the new cultural setting.

\section{Limits of learning}

Learning from distant cultures is not without limits. Companies will learn from their local experience only if the new knowledge overlaps with or is related to their existing knowledge (Cohen and Levinthal, 1990). Learning skills - the ability to interpret and assimilate new information - like problem-solving skills, can only be transferred across bodies of knowledge that are organised and expressed in similar ways (Cohen and Levinthal, 1990). Some overlap between the company's knowledge base and the knowledge required for operating in the new cultural bloc is needed for the company to be able to interpret the local experience, assimilate it, and put it to commercial ends (e.g., improve the performance of subsequent entries). From an organisational learning perspective (Cohen and Levinthal, 1990), either one of two extreme situations ('worlds') may exist:

(1) The overlap between the cultural knowledge of the company and the knowledge needed to operate in a new, distant cultural bloc is small or negligible. So little knowledge can be absorbed from the local experience, assimilated, and put to commercial use, resulting in few if any performance improvements of subsequent expansions in the cultural bloc. This situation corresponds with a world where the culture of the home country of an internationalising firm and the culture in a distant cultural bloc are very different (i.e., little overlap).

(2) Alternatively, the overlap between the company's knowledge base and the knowledge required for the new culture bloc may be very large. In this case, it is easy to absorb the remaining knowledge, but there is little left to learn. This corresponds with a world where cultures are, or have become, very similar. Again, the company learns little in the new cultural bloc, and will see small performance improvements in subsequent expansions.

Organisational learning theory implies that learning is most effective in the middle between these two extremes, when some portion of the new knowledge is closely related to the knowledge base of the company but the remaining portion, though still related, is fairly diverse (Cohen and Levinthal, 1990). Learning is optimal if new knowledge is neither too similar to, nor too different from, existing knowledge 
(Thomas et al., 2001). Consistent with this idea, Hayward (2002) found that companies were most successful if new acquisitions were moderately related to the existing knowledge base.

This means, in our context, that learning from other cultural blocs will be greatest 'in the middle', when the overlap between the company's cultural knowledge upon entry is fairly large, yet when there is still enough left to learn. Later on we shall test which of the two worlds most resembles the real world. In world 1, gaining experience in other cultures before entering a distant culture will increase the overlap at entry (that is, it moves the company to the 'middle') and increase the learning from local experience. Sequential entry strategies and gaining international experience first is important because it facilitates local learning. Alternatively, in world 2, gaining international experience before entry increases the overlap even further (pushes the company further away from the middle), leaving even less to learn: that is, it decreases local learning. In this world sequential internationalisation strategies are less relevant (because they diminish local learning).

\section{Hypotheses}

\section{Expansions within a cultural bloc}

Much knowledge about cultures is tacit in nature, and can be learned only from experience, essentially as a by-product of foreign operations. If a company invests in another country in the same cultural bloc we expect it to remain relatively close to its existing knowledge base of foreign cultures, defined earlier as its rules, procedures conventions, and strategies for how to operate in foreign cultures, as well as the underlying structure of knowledge and beliefs (Levitt and March, 1988; Greenwood and Hinings, 1993). As a result, companies may improve and refine their routines and knowledge (Ahuja and Lampert, 2001; Zollo and Winter, 2002) - in other words, their mental models of cultures (i.e., concepts and the linkages between them; Huff, 1990) - rather than develop new ones (Cohen and Levinthal, 1990). This is consistent with a strategy of exploitation. Hence we expect that companies will benefit from prior experience in the same cultural bloc when investing in other countries in that bloc.

Hypothesis 1a: Experience in a cultural bloc improves the performance of later investments in other countries in the same cultural bloc.
Support for this baseline hypothesis was previously found in studies using archival FDI data from the 1960s, 1970s and 1980s (Barkema et al., 1996). Our theory implies that the hypothesis is still valid for the current time frame.

\section{Contractual experience}

We expect that contractual modes such as sales agents, licensing, and franchising will serve as a platform from which to learn about the new culture. A local party basically sets up and runs local operations, dealing with local cultural and regulatory issues, and so the foreign company needs to adjust only a limited range of its knowledge and routines in order to operate locally. It may learn from its experience with the local partner, and from observing how the local partner handles its own business partners, and local and national governmental officials. This knowledge can be exploited later on when investing in the country. Hence entering through sales agents, licensing, or franchising improves the performance of subsequent FDI in a country. Our theory implies that the internationalisation process still matters, in the sense that companies benefit from their contractual experience when investing in the same cultural environment later.

Hypothesis 1b: Local contractual experience, through sales agents, licensing, or franchising, improves the performance of subsequent FDI in the same country, as compared with an absence of such prior experience.

\section{FDI experience}

Once a company has gained experience with a local culture through contractual means, it may extend this experience through FDI in the same country. This is also consistent with a strategy of exploitation, where a company searches for expansion opportunities in the neighbourhood of its current cultural knowledge and routines, and refines its existing knowledge (Cyert and March, 1963; Ahuja and Lampert, 2001; Zollo and Winter, 2002). This strategy is similar to the expansion process suggested by the Uppsala model with its emphasis on low risk and short-term performance.

Hypothesis 1c: When doing FDI, companies benefit from previous FDI experience in the same country.

Prior work supporting this hypothesis used archival data from the 1960s, 1970s and 1980s (Li, 1995; 
Barkema et al., 1996; Shaver et al., 1997). Our theory implies that this prediction still holds.

\section{Faster entry and learning}

Research in the 1970s and 1980s found that companies enter countries incrementally, first using contractual entries, and then FDI (Johanson and Wiedersheim-Paul, 1975). However, if a company makes a larger step when entering a country, skipping the intermediate contractual phase and doing FDI immediately, what are the implications for learning from and about the local culture?

The company still enters the same national culture, but faster: that is, the jump from its current cultural knowledge base is basically the same. However, it now has to deal with a variety of local parties, including suppliers, customers and governments, without benefiting from first learning about the local culture with a local partner (as in sales agents, franchising, or licensing). As a result, the performance of its initial FDI in the country will be lower (as Hypothesis 1b implies). However, lower performance of FDI leads to more intensive effort or 'problemistic search' for new solutions, and to better knowledge and routines (Cyert and March, 1963; Cohen and Levinthal, 1990) - that is, to more learning about the local culture. Hence, compared with a strategy where FDI is preceded by contractual experience, we expect that proceeding immediately to FDI implies greater learning about the local culture from initial FDI projects and stronger performance increases of subsequent FDI.

Hypothesis 2: Companies that enter a country through immediate FDI benefit more from their FDI experience when undertaking subsequent FDI in the same country than do companies whose initial entry was through contractual means, such as sales agents, licensing or franchising.

Whatever the specific entry strategy - FDI preceded by contractual means or not - we expect companies to learn from multiple FDI projects in a country. Each FDI project will be different, as every new experience will increase knowledge about how to operate in the local culture (March et al., 1991). FDI projects are complex cultural experiences, which involve setting up local operations and dealing with local parties such as suppliers, customers, governments or partners, and something new can be learned from each of these experiences (Levitt and March, 1988; Haunschild and Sullivan, 2002). Because of the ambiguous nature of these cultural experiences, multiple projects are needed to figure out cause-and-effect relationships related to local cultures and how they influence performance.

\section{Entering a new cultural bloc}

\section{International experience}

Not everything may be new when entering a new cultural bloc, particularly if companies have gained international experience first. Traditionally, companies gained this experience when expanding in an incremental fashion from the home country to new (non-adjacent) countries or blocs (Johanson and Wiedersheim-Paul, 1975; Benito and Gripsrud, 1992), but this does not exclude the possibility that companies can learn from experience gathered further away as well. Companies with international experience will therefore be more successful when investing in a new cultural bloc (Johanson and Wiedersheim-Paul, 1975; Erramilli, 1991; Benito and Gripsrud, 1992). These companies have a richer and more diverse knowledge base of how to handle foreign environments and cultures (Miller and Chen, 1994, 1996), and are more likely to transfer their routines and problem-solving skills to the new setting, enhancing FDI performance. International experience may also promote the development of new and creative solutions for handling cultures (Hargadon and Fanelli, 2002), increasing the likelihood that the company will discover profitable business opportunities. Hence we expect that international experience will improve FDI performance in a new cultural bloc.

Hypothesis 3: International experience improves the performance of FDI in a new cultural bloc.

\section{International experience and local learning}

So far we have assumed that all companies learn equally from their experience in a new cultural bloc (Hypotheses 1a, 1b, 1c and 2). However, our theory implies ('limits on learning') that learning is contingent on how much a company's knowledge base overlaps with the knowledge required in the new cultural bloc. We therefore now take a step back and consider this contingency.

As already mentioned, in theory one of two situations may exist. In World 1 (where the cultures of the home countries of internationalising firms and distant cultural blocs are very different), gaining experience in other countries first will increase the overlap upon entry, and hence increase learning from local experience (including 
expansions in other countries in the same bloc, local contractual and FDI experience, and a stronger substitution effect implied by Hypothesis 2). In World 2 (where cultures are or have become similar), gaining experience in other countries first will further increase the overlap when entering the new bloc, leaving even less to learn, and hence decreasing the learning from the local experience.

In sum, our theory implies that the strength of local learning effects, from CEE experience, contractual and FDI experience (and the substitution effect), in terms of the improved performance of later FDI, is contingent on the company's international experience. This rejects the null hypothesis that the beneficial effect on later FDI is independent of the company's international experience. We cannot predict, on theoretical grounds alone, whether companies with international experience will learn more from their local experience, or less than companies with less international experience - that is, whether world 1 or 2 exists in practice: it is an empirical matter. However, our theory does imply that the learning effects differ in a consistent way. They all go in the same direction: that is, they become either weaker or stronger as a function of international experience.

Hypothesis 4: Learning from experience in a new cultural bloc - that is, the impact of learning from CEE experience, contractual experience, FDI experience and the substitution effect on the performance of subsequent FDI - is contingent on a company's international experience.

\section{Methods}

\section{Sample selection and data collection}

We tested our hypotheses on foreign entries by Dutch companies into CEE. This cultural bloc offers an interesting quasi-experimental setting (Meyer and Peng, 2005), because FDI there before 1989 was virtually impossible. Hence all foreign companies in the region have a relatively short history of FDI, enabling us to examine the learning effects from first-time entries. For Dutch companies, CEE is neither the closest cultural bloc (Nordic, AngloSaxon or Germanic) nor the most remote (South Asia or Africa).

We collected data through mail questionnaires on the foreign entries of companies from one home country - The Netherlands - which allows us to control for potential sources of variation in the home country of expanding companies. In the sample period, from 1989 to 1998, The Netherlands was the fifth largest foreign investor in this region (World Bank, 1996; Meyer, 1998). We searched for all the foreign direct investments in CEE of Dutch companies with more than 100 employees, in archival sources such as Het Financieele Dagblad (the Dutch equivalent of the Wall Street Journal), NRC Handelsblad (the principal Dutch national newspaper), and the database Reach. This led to the identification of 242 companies with investments in at least one of six selected countries: the Czech Republic, Hungary, Poland, Romania, the Russian Federation, and Ukraine. The countries selected were the top four receivers of Dutch FDI in the period of interest (Poland, Hungary, Czech Republic and Russia) plus two countries that received significantly less FDI: Ukraine and Romania. The selection also includes countries from Central Europe as well as countries that were formerly part of the Soviet Union, and shows meaningful variation regarding language and culture.

Informative phone calls led to the exclusion of companies that had shifted the coordination of subsidiaries in the region to offices in third countries, and companies that were Dutch by registration but which were owned by a foreign parent company that coordinated activities in CEE. This left 159 potential respondent companies. The phone calls were also used to identify the most appropriate person to respond to the survey, typically a general manager, regional manager, or sales or marketing manager with responsibility for entries into CEE.

After a pre-test in interviews with managers responsible for subsidiaries in CEE we rephrased some questions in the questionnaire. Each respondent was asked to answer questions about two subsidiaries in different countries (if available, and selected randomly by the researchers from archival data). Separate answer sheets provided names, functions, and other personal details of the respondents, revealing that, given the description of their function, they were capable of providing the information we were seeking.

Of the 159 individuals to whom we sent a questionnaire, 84 completed and returned them (a $53 \%$ response rate), providing information on 125 subsidiaries. We excluded 26 subsidiaries from consideration because of incomplete data, leaving 99 subsidiaries, of which 83 were active in a wide range of manufacturing industries, such as the chemical industry, consumer electronics, food and beverages, and horticulture, and 16 were service 
companies, such as banks and insurance, consultancy, and transportation companies. Because manufacturing companies typically integrate into local networks of suppliers and customers (often other companies), they may have expansion patterns that are different from those of service companies (Johanson and Mattson, 1985). For this reason, manufacturing companies are often investigated separately (Buckley et al., 1978; Hedlund and Kverneland, 1983; Erramilli and Rao, 1993; Eriksson et al., 1997). To keep our sample as homogeneous as possible, we chose to examine only subsidiaries of manufacturing companies, giving us a final sample of 83 subsidiaries. Of these, 80 were reported to have sales activities, and 42 also had manufacturing facilities. Over $75 \%$ of the subsidiaries in the sample were established mainly for market-seeking reasons (our survey, not reported here).

\section{Variables}

\section{Dependent variable}

FDI performance: In a study in which they measured IJV performance, Geringer and Hebert (1991) found that subjective performance measures were significantly and positively correlated with objective measures, especially IJV survival and IJV duration. However, in view of the relative youth of the average FDI in CEE, performance measures as survival or longevity are not appropriate for our study. The performance of new foreign subsidiaries is instead best measured using perceptual measures (Birkinshaw and Morrison, 1995). Geringer and Hebert (1991) used a 15-item Likert scale measuring the perceived present performance in comparison with initial projections for IJV. Seven of these 15 items (sales level, market share, profitability, marketing, distribution, reputation, and overall performance) correlated with two objective measures of performance: survival and duration. It was not possible in the current study to replicate all seven of these performance indicators for all subsidiaries, as some subsidiaries were not responsible for marketing or distributing their products (our survey, results not reported here). We therefore selected the five items from the original study by Geringer and Hebert (1991) that were applicable to all observations, considering their local activities. Likert-type scales were used to assess the managers' perceptions of the performance of the subsidiaries with regard to sales level, market share, profitability, reputation, and overall performance, all compared with expectations at the time of entry.

\section{Independent variables}

We measured the international experience of a company as the log of its total number of foreign subsidiaries not in the CEE bloc at the time of entry into the host market (Gatignon and Anderson, 1988; Barkema et al., 1996). We took the log of the number of subsidiaries to capture the fact that companies learn from their experience at a decreasing rate (Yelle, 1979).

Contractual experience in the host country: We asked each respondent to specify the first activities of the company in the host country. A dummy variable was created, with a value of 1 if the company started activities in the host country using licensing, franchising, or other contractual agreements, and 0 otherwise.

For the company's host country FDI experience, we used the $\log$ of the number of subsidiaries of the company in the host country in the year of entry of the focal FDI. We operationalised experience within the CEE bloc as the log of the number of subsidiaries of the company in CEE countries in the year of entry.

\section{Control variables}

First, we included the cultural distance of the host country from The Netherlands. Prior internationalisation researchers have used 'psychic distance' rankings of countries (Johanson and Wiedersheim-Paul, 1975; Nordström, 1991) or the Kogut and Singh (1988) index based on Hofstede's work (Benito and Gripsrud, 1992; Li, 1995; Barkema et al., 1996). The host countries in our study were not included in the original Hofstede study (1980), but we received their scores on the four dimensions from the Institute for Research on Intercultural Cooperation (IRIC, cofounded by Hofstede). Further, we controlled for differences in economic growth between countries using the host country's GDP growth in the year of entry (EBRD, 1997). In prior studies on entry strategies in CEE, economic indicators of the transition process were found to have an effect (Meyer, 2001; Wooster, 2006). Finally, we included a dummy variable if the focal FDI had production activities, to control for possible differences between sales and production subsidiaries, because previous studies on entry into CEE have found that the activities of the subsidiary influenced local performance (e.g., Meyer, 2001).

\section{Analysis}

We first tested, using confirmatory factor analysis, whether the indicators of performance captured a single underlying construct. The individual item scores were multiplied by their corresponding 
factor loadings and summed to one variable. The hypotheses were tested using OLS. To avoid multicollinearity problems due to interaction effects, the variable host-country FDI experience is centred (Aiken and West, 1991). If the interaction effect is included, the main effect should be interpreted as a conditional effect rather than as an independent effect on the dependent performance variable (Friedrich, 1982; Darlington, 1990). We checked for potential multicollinearity by examining the variance inflation factors and found them all to be at acceptable levels, with VIFs $<3.0$ (Neter et al., 1996). Finally, we used White covariance matrix estimators because they do not require specific assumptions about the form of heteroskedasticity.

\section{Results}

\section{Factor analysis}

As mentioned, we first conducted a confirmatory factor analysis to explore the underlying structure of the five performance indicators (Cronbach's alpha $=0.82$ ). The indicators captured one single factor explaining $59.7 \%$ of the variance. Each indicator loaded $>0.7$ on this factor (Table 1 ).

Descriptive statistics of the dependent and independent variables are given in Table 2 .

Table 1 Factor loadings: FDI performance

Performance of the subsidiary compared with expectations at the start

\begin{tabular}{ll}
\hline Sales & 0.814 \\
Market share & 0.748 \\
Profit & 0.728 \\
Reputation & 0.771 \\
General performance & 0.883 \\
\hline
\end{tabular}

\section{Hypotheses testing}

Hypothesis 1a implies that prior CEE experience has a positive effect on FDI performance. The positive, significant effect $(P<0.10)$ of CEE experience on FDI performance in models 1 and 2 (Table 3) corroborates this hypothesis.

Hypothesis $1 \mathrm{~b}$ implies that prior contractual experience in the country improves FDI performance. The results in the first column of Table 3 corroborate Hypothesis $1 \mathrm{~b}$ : the effect of contractual experience is positive and marginally significant $(P<0.10)$. Consistent with Hypothesis 1c, FDI experience in the host country increases FDI performance (a positive, significant effect of host FDI experience in both models). Hypothesis 2 predicts that companies will benefit less from their local FDI experience if it is preceded by contractual entry modes. As model 2 shows, the interaction effect of contractual experience and host FDI

Table 3 Results of regression analyses

\begin{tabular}{lcc}
\hline & 1 & 2 \\
\hline Cultural distance & $-0.166^{\dagger}$ & -0.158 \\
GDP growth & -0.132 & -0.092 \\
Production activities & $0.266^{* *}$ & $0.306^{* *}$ \\
International experience & $0.244^{*}$ & $0.213^{*}$ \\
CEE experience & $0.151^{\dagger}$ & $0.160^{\dagger}$ \\
Host FDI experience & $0.253^{*}$ & $0.325^{* *}$ \\
Host contractual experience & $0.144^{\dagger}$ & 0.064 \\
Host contractual experience $\times$ Host FDI & & $-0.242^{* *}$ \\
experience & & \\
& & \\
Adjusted $R^{2}$ & 0.224 & 0.262 \\
$F$ value & $5.18^{* * *}$ & $5.56^{* * *}$ \\
Number of observations & 83 & 83 \\
\hline${ }^{\dagger} P<0.10 ;{ }^{*} P<0.05 ;{ }^{* *} P<0.01 ;{ }^{* * *} P<0.001$ (one-tailed if hypothesised).
\end{tabular}

Table 2 Descriptive statistics and correlations

\begin{tabular}{llrrrrrrrrr}
\hline & Mean & s.d. & 1 & 2 & 3 & 4 & 5 & 6 & 7 & 8 \\
\hline 1 FDI performance & 2.87 & 0.43 & & & & & & & \\
2 & Cultural distance & 2.61 & 0.97 & -0.048 & & & & & & \\
3 & GDP growth & -0.75 & 6.24 & -0.135 & $-0.331^{*}$ & & & & & \\
4 & Production activities & 0.51 & 0.51 & 0.207 & 0.115 & -0.029 & & & & \\
5 & International experience & 21.78 & 36.33 & $0.328^{*}$ & 0.013 & -0.029 & -0.114 & & & \\
6 & CEE experience & 1.12 & 1.45 & 0.207 & 0.072 & -0.070 & -0.142 & $0.272^{*}$ & & \\
7 & Host FDI experience & 1.70 & 1.69 & $0.347^{*}$ & 0.037 & -0.105 & 0.007 & $0.327^{*}$ & 0.145 & \\
8 Host contractual experience & 0.18 & 0.39 & 0.076 & 0.143 & -0.039 & 0.026 & -0.076 & -0.044 & -0.123 \\
9 & Host contractual experience $\times$ Host & 0.01 & 0.08 & -0.126 & -0.035 & 0.131 & 0.170 & -0.018 & 0.029 & $0.286^{*}-0.351^{*}$ \\
& FDI experience & & & & & & & & & \\
\hline
\end{tabular}

The table shows means and standard deviations of international experience, CEE experience, and host-country experience before the log was taken and the values were centred.

${ }^{*}$ Correlation is significant at the 0.05 level (2-tailed). 
experience impacts negatively on FDI performance $(P<0.01)$, corroborating Hypothesis 2 .

Figure 1 graphically represents the conditional effects of contractual experience of model 2 for $\mathrm{FDI}=0,1$ and 2 . We calculated the significance of the contractual experience effects at these FDI levels (Friedrich, 1982; Finney et al., 1984). We found that with FDI experience $=0$ or 1 , the (conditional) effect of contractual experience on FDI performance is positive and significant. At these levels companies benefit from their contractual experience, improving the performance of later FDI. With FDI=2, the effect of contractual experience becomes insignificant: that is, the knowledge from contractual activities has been substituted by more learning from FDI experience in the absence of contractual experience. Apparently, companies benefited, in terms of perfor-

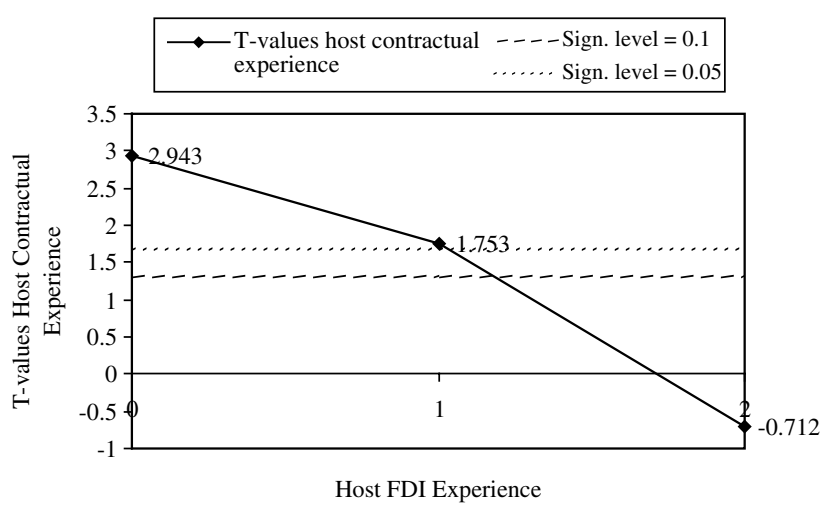

Figure 1 The conditional effect of contractual experience on current FDI performance at different levels of FDI experience in the host country. mance of FDI projects, only from their prior contractual expansion with their first two FDI projects in a CEE country. Finally, Hypothesis 3, that international experience improves FDI performance, was also corroborated $(P<0.05) .{ }^{1}$

\section{International experience}

In order to understand better how international experience impacts on learning in new cultural blocs, we divided our sample in two equal subsets, one with above-average international experience (Table 4, column 1), and one with below-average international experience (column 2). Our theory suggests that we should see systemic differences in local learning in the two subsets, but does not predict in which subset the learning effects are stronger; it depends on whether world 1 or 2 applies.

The estimates in column 1 show that, for companies with above-average international experience, the effects of both CEE experience and FDI experience are positive and significant. Again, the conditional effect of contractual experience at low levels of FDI is positive and significant (for FDI $<2$ ), and we find a significant substitution effect. Further, it appears that, once companies have considerable international experience, they no longer benefit from even higher levels of international experience in terms of the direct effect on FDI performance: that is, there is no significant effect of international experience. Apparently, at such high levels of international experience, further international experience no longer improves FDI performance.

In contrast, as column 2 shows, companies with relatively little international experience $d o$ benefit

Table 4 Results of regression analyses for sub-samples of companies: above average (Models 1 and 3) and below average (Models 2 and 4) international experience

\begin{tabular}{|c|c|c|c|c|}
\hline & $\begin{array}{c}\text { 1: Above average, } \\
\text { full model }\end{array}$ & $\begin{array}{c}\text { 2: Below average, } \\
\text { full model }\end{array}$ & $\begin{array}{c}\text { 3: Above average, } \\
\text { experience variables only }\end{array}$ & $\begin{array}{l}\text { 4: Below average, } \\
\text { experience variables only }\end{array}$ \\
\hline Cultural distance & -0.098 & -0.176 & & \\
\hline GDP growth & 0.068 & $-0.287^{\dagger}$ & & \\
\hline Production activities & $0.321^{*}$ & $0.308^{\dagger}$ & & \\
\hline International experience & -0.036 & $0.318^{*}$ & & \\
\hline CEE experience & $0.205^{\dagger}$ & 0.102 & $0.209^{\dagger}$ & 0.054 \\
\hline Host FDI experience & $0.513^{* *}$ & 0.170 & $0.461^{* *}$ & 0.223 \\
\hline Host contractual experience & 0.166 & -0.050 & 0.143 & -0.137 \\
\hline $\begin{array}{l}\text { Host contractual experience } \times \\
\text { Host FDI experience }\end{array}$ & $-0.350^{\star *}$ & -0.209 & $-0.242^{*}$ & -0.356 \\
\hline Adjusted $R^{2}$ & 0.234 & 0.155 & 0.200 & 0.004 \\
\hline$F$ value & $3.16^{* *}$ & $1.94^{\dagger}$ & $2.95^{\star}$ & 0.96 \\
\hline Number of observations & 41 & 42 & 41 & 42 \\
\hline
\end{tabular}

${ }^{\dagger} P<0.10 ;{ }^{*} P<0.05 ;{ }^{* *} P<0.01 ;{ }^{* *} P<0.001$ (one-tailed if hypothesized). 
from more international experience: that is, the direct effect is positive and significant $(P<0.05)$. However, at these relatively low levels of international experience, companies appear to benefit neither from their experience in other CEE countries nor from their local contractual experience or their FDI experience, nor is there a substitution effect. None of these effects is significant in model 2.

To further check the robustness of these findings, we performed sensitivity analyses testing models on the split samples including the four experience variables only (CEE bloc experience, host FDI and contractual experience, and the substitution effect). ${ }^{2}$ Columns 3 and 4 in Table 4 show the same support for our hypotheses: companies with aboveaverage international experience benefit from local experiential knowledge, but companies with belowaverage international experience do not. In fact, for this last subsample the variance explained by local experience (i.e., the four experience variables jointly) becomes close to 0: 0.004 as compared with 0.200 for the subset with above average international experience. A univariate regression model testing the effect of international experience (only) on the performance of local subsidiaries for companies with below-average international experience supported the findings in model 2: $\beta=3.13(P<0.05)$, and $F=3.32(P<0.07)$.

Apparently, in the case of Dutch companies entering a non-adjacent cultural bloc such as CEE, international experience upon entry helped in interpreting local experience and in local learning. This is consistent with what was earlier described as world 1, where cultural blocs are substantially different, and gaining international experience first before entering a non-adjacent cultural bloc facilitates local learning: that is, a world where sequential entry strategies still matter.

\section{Discussion and conclusions}

We used the exploitation/exploration lens to examine how companies internationalise to foreign cultural environments. Our theory was tested on evidence on entries into CEE, which opened up in 1989, enabling us to study learning from initial entries. Exploitation corresponds to expanding within a cultural bloc (Ronen and Shenkar, 1985; Barkema et al., 1996) and refining a company's knowledge base in subsequent entries. Consistent with our theory, we found that companies benefited from their experience when expanding to other countries in the same bloc. Entering through contractual means first (licensing, franchising, or sales agents) improved the performance of subsequent FDI. This confirms earlier research, using data from up to the 1980s, that predicted incremental expansion patterns. Immediate FDI (that is, skipping contractual forms) leads to lower FDI performance, but companies also learned more from their initial investment projects, and on average caught up after two FDI projects. This is consistent with an early study by Benito and Gripsrud (1992) reporting that FDI expansion patterns suggest learning, but not of the incremental kind envisaged by traditional internationalization process models.

We also studied exploration - going to a new cultural bloc, which may involve learning new cultural concepts (Hofstede and Bond, 1988) and new linkages with other concepts, underlying new rules, procedures, conventions and strategies (which may subsequently be improved as companies refine this knowledge and these routines when expanding in the new bloc). Our evidence suggests that, even today, there are constraints on how far companies can 'jump' (Gavetti and Levinthal, 2000) from their cultural knowledge base. Dutch companies entering CEE with substantial international experience were able to learn and improve the performance of their FDI. In contrast, no significant learning effects were found for companies without substantial international experience. Apparently, sequential expansion paths may still increase local learning and success. Interestingly, this result was found for an intermediately remote cultural bloc such as CEE, which is further away than the Nordic, Germanic, or Anglo-Saxon cultural blocs for Dutch companies, but closer than the South-East Asian and African cultural blocs.

Our study suggests that companies have a strategic choice. Successful companies strike a long-term balance between exploitation and exploration (March, 1991). They may expand more deeply into well-known cultural blocs, exploiting their knowledge base and maximising short-term performance. Or they may enter new cultural blocs, implying lower short-term performance but learning to enhance future success. Depending on their strategy and resources, they may either do both, or do them sequentially, where the optimal balance may depend on industry conditions - for instance, the extent to which the firms in the industry are engaged in a race for global dominance. However, we also discovered constraints on the strategic freedom (i.e., no jumps immediately from the home country to distant cultures). In sum, our study helps in understanding the strategic choices 
that are available for firms expanding abroad, the implications of these choices for short-term performance and learning, and the constraints for the strategic freedom that these firms face.

Companies may also choose to make greater steps into cultural 'space' for reasons other than being involved in a race. Their business model may not allow for contractual modes such as licensing, franchising, or sales agents, and require immediate FDI when searching for clients in new countries, when seeking to reconfigure the value chain for instance by moving manufacturing abroad (Vernon, 1966) - or when creating options to tap into local knowledge of technologies and markets (Bartlett and Ghoshal, 1989; Barkema and Vermeulen, 1998; Doz et al., 2001; Murtha et al., 2001). Our study is relevant for these choices as well. Independent of the particular strategic motive, companies need to learn about the local culture. Our study suggests that companies may learn even more about local cultures when they take greater steps, but that the steps should not be too large, or companies may enjoy limited learning and performance improvements in a distant cultural bloc.

Finally, our results suggest a (direct) effect of international experience on FDI performance for the subsample of firms with relatively little international experience; no significant effect was found for internationally experienced firms. In contrast, the latter firms were able to absorb their local experience in the new cultural bloc, whereas the internationally less experienced firms seemed unable to do so. Taken together, this suggests that routines that companies can use in other cultural blocs as well are already built after a few international expansions, and that their refinement and the resulting performance improvements exhaust relatively quickly (implying no further improvement for internationally experienced firms). In contrast, the skill to absorb new concepts and new linkages between concepts, and translate them into new rules, procedures, conventions, and strategies that work in a new cultural bloc, is a complex learning skill that begins to develop only after a certain number of international expansions (only for internationally experienced firms) and continues to improve over a longer domain of international experiences. More specifically, the results of models 1 and 3 in Table 4 (in contrast to those of models 2 and 4 ) show learning from contractual experience, FDI experience, and a substitution effect. Apparently, firms with rich international experience, in particular, have a choice, in terms of either a slow, low-risk entry strategy using contractual entries first (if their business model allows it), or direct FDI, sacrificing performance on their first investments but learning more through their faster entry and catching up rapidly with firms that used contractual entry first. ${ }^{3}$

\section{The internationalisation debate}

Does learning about new environments still matter, or have other competences of companies become the dominant basis for competition and for strategic decisions (Yip et al., 2000)? The exchange of people, ideas and information has increased over recent decades, and practices such as food, fashion, music, and education systems are converging (Levitt, 1983). Companies no longer expand incrementally as they did in the 1970s; they think more in terms of cultural blocs rather than countries, and in many industries race to conquer new countries and regions first (Barkema et al., 2002). Hence the debate in the JIBS Emerging Frontiers Conference: Are internationalisation processes - and internationalisation process models - still relevant?

Our study addressed these questions head on. We found, using data on fairly recent first-time entries, that companies benefited from their contractual experience when doing FDI later. If they skipped the contractual mode, their initial FDI performed less well, but they learned more from these projects. They learned from other countries in the same cultural bloc. If they moved to a non-adjacent cultural bloc, such as CEE for Dutch companies, they learned significantly from their local experience only if they had gained international experience first. All these results suggest that internationalisation processes still matter - perhaps even more so today, if the increasing pace of globalisation and innovation (Brown and Eisenhardt, 1997; Hitt et al., 1998; Murtha et al., 2001) renders a strategy of exploration more relevant. It is important to know what the cultural constraints of this strategy are, because reconfiguring the value chain, tapping into distant knowledge of technology and market needs, or other strategic steps all require an understanding of the foreign cultural environment.

\section{Limitations and suggestions for further research}

Naturally, our study has limitations. We used the exploitation/exploration lens to evaluate two alternative sets of strategies - moving to a new cultural bloc, or expanding within a cultural bloc - using contractual modes or FDI. In future studies, 
researchers could use this lens to evaluate alternative strategies of exploitation and exploration for internationalising companies. We measured performance using subjective performance measures. Given that investments need a few years to become profitable, or to reach their strategic goals, subjective rather than objective measures such as survival or the profitability of the venture seemed appropriate, particularly because of this study's interest in recent entries into CEE. However, future studies using objective performance measures would add to the current study. Furthermore, our study examined companies based in one home country - the Netherlands - entering one cultural bloc - CEE. Evidence from other cultural and institutional environments would add to the findings of our study. For reasons of sample homogeneity, we focused on manufacturing firms only. Future studies can contribute by comparing the expansion patterns of manufacturing firms with those of service firms.

Companies may also use knowledge of foreign cultures gained in other ways than through expansion experience - for instance, by sending employees who were born in the host country (e.g., Tesco's policy in CEE) or by hiring people locally instead of using expatriates. However, there are constraints on hiring local managers, as companies seek to build combinations of firm-specific and local knowledge as a basis for competitive advantage. Increasingly, managers and other employees have gained international experience in previous companies they worked for, which may enable their present companies to internationalise faster: compare for instance young high-tech companies (Autio et al., 2000). Our sample, drawn from the population of all Dutch firms internationalising to CEE, contained few such cases. Finally, we focused on the exploitation and exploration of cultural knowledge collected through experience. However, experiential learning is only one of the learning mechanisms that companies use in building a fully fledged MNC (Levitt and March, 1988; Gavetti and Levinthal, 2000). Future research might improve our understanding of different ways of learning, and what the strategic implications are for internationalisation, to the success of modern MNCs.

\section{Acknowledgements}

We should like to thank Ulf Holm and Mario Schijven for their valuable insights. We are also grateful for the insightful comments of the three anonymous JIBS reviewers, and for the excellent guidance of co-guest editor Thomas Hutzschenreuter and Editor-in-Chief Arie Y. Lewin.

\section{Notes}

${ }^{1}$ As a robustness check, we also tested models with control variables for size (number of employees), level of ownership (full or shared ownership) and year of founding of the subsidiary. These tests showed the same support for our hypotheses. We also tested whether our results were driven by individual observations. We performed outlier analyses by examining student residuals and using the jackknife procedure ( $n$-1 samples). These analyses showed that our results were not driven by outliers; we found the same significant effects as presented in Table 3.

${ }^{2}$ Despite the fact that 'a general rule is that the ratio (of sample size to number of independent variables) should never fall below 5:1, meaning that five observations are made for each independent variable in the variate' (Hair et al., 2006: 196), preferably this ratio should be 10:1 or larger. Models 3 and 4 in Table 4 conform to this more stringent rule. Finally, the same outlier analyses regarding Table 4 as performed earlier for Table 3 showed that our results were not driven by outliers.

${ }^{3}$ We should like to thank the Acting Editor for bringing this to our attention.

\section{References}

Aharoni, Y. (1966) The Foreign Direct Investment Decision Process, Harvard University Press: Boston.

Ahuja, G. and Lampert, C.M. (2001) 'Entrepreneurship in the large corporation: a longitudinal study of how established firms create breakthrough inventions', Strategic Management Journal 22(6-7): 521-543.

Aiken, L.S. and West, S.G. (1991) Multiple Regression: Testing and Interpreting Interactions, Sage: Newbury Park.

Anderson, E. and Gatignon, H. (1986) 'Modes of foreign entry: a transaction cost analysis and propositions', Journal of International Business Studies 17(3): 1-24.

Autio, E., Sapienza, H.J. and Almeida, J.G. (2000) 'Effects of age at entry, knowledge intensity, and imitability on international growth', Academy of Management Journal 43(5): 909-924.

Barkema, H.G. and Vermeulen, F. (1997) 'What differences in the cultural backgrounds of partners are detrimental for international joint ventures?' Journal of International Business Studies 28(4): 845-864.

Barkema, H.G. and Vermeulen, F. (1998) 'International expansion through start-up or acquisition: a learning perspective', Academy of Management Journal 41(1): 7-26. 
Barkema, H.G., Baum, J.A.C. and Mannix, E.A. (2002) 'Management challenges in a new time', Academy of Management Journal 45(5): 916-930.

Barkema, H.G., Bell, J.H.J. and Pennings, J.M. (1996) 'Foreign entry, cultural barriers and learning', Strategic Management Journal 17(2): 151-166.

Bartlett, C.A. and Ghoshal, S. (1989) Managing across Borders: The Transnational Solution, Hutchinson Business Books: London.

Baum, J.A.C., Li, S.X. and Usher, J.M. (2000) 'Making the next move: how experiential and vicarious learning shape the locations of chains' acquisitions", Administrative Science Quarterly 45(4): 766-801.

Beamish, P.W. and Wang, H.Y. (1989) 'Investing in China via joint ventures', Management International Review 29(1): 57-64.

Benito, G.R.G. and Gripsrud, G. (1992) 'The expansion of foreign direct investments: discrete rational location choices or a cultural learning process?' Journal of International Business Studies 23(3): 461-476.

Benner, M.J. and Tushman, M.L. (2002) 'Process management and technological innovation: a longitudinal study of the photography and paint industries', Administrative Science Quarterly 47(4): 676-706.

Birkinshaw, J.M. and Morrison, A.J. (1995) 'Configurations of strategy and structure in subsidiaries of multinational corporations', Journal of International Business Studies 26(4): 729-753.

Brown, S.L. and Eisenhardt, K.M. (1997) 'The art of continuous change: linking complexity theory and time-paced evolution in relentlessly shifting organizations', Administrative Science Quarterly 42(1): 1-34.

Buckley, P.J. and Ghauri, P.N. (2004) 'Globalisation, economic geography and the strategy of multinational enterprises', Journal of International Business Studies 35(2): 81-98.

Buckley, P.J., Newbould, G.D. and Thurwell, J. (1978) Going International: The Experience of Smaller Companies Overseas, Associated Business Press: London.

Cohen, W.M. and Levinthal, D.A. (1990) 'Absorptive capacity: a new perspective on learning and innovation', Administrative Science Quarterly 35(1): 128-152.

Cyert, R.M. and March, J.G. (1963) A Behavioural Theory of the Firm, Blackwell Business: Cambridge.

Darlington, R.B. (1990) Regression and Linear Models, McGrawHill: New York.

Delios, A. and Beamish, P.W. (2001) 'Survival and profitability: the roles of experience and intangible assets in foreign subsidiary performance', Academy of Management Journal 44(5): 1028-1038.

Delios, A. and Henisz, W.J. (2003) 'Political hazards, experience, and sequential entry strategies: the international expansion of Japanese firms 1980-1998', Strategic Management Journal 24(11): 1153-1164.

Doz, Y.L., Santos, J. and Williamson, P. (2001) From Global to Metanational: How Companies Win in the Knowledge Economy, Harvard Business School Press: Boston.

EBRD (1997) Transition Report: Enterprise Performance and Growth, European Bank for Reconstruction and Development: London.

Engwall, L. and Wallenstål, M. (1988) 'Tit for tat in small steps: the internationalization of Swedish banks', Scandinavian Journal of Management 4(2): 147-155.

Eriksson, K., Johanson, J., Majkgård, A. and Sharma, D. (1997) 'Experiential knowledge and cost in the internationalization process', Journal of International Business Studies 28(2): 337-360.

Erramilli, M.K. (1991) 'The experience factor in foreign market entry behavior of service firms', Journal of International Business Studies 22(3): 479-501.

Erramilli, M.K. and Rao, C.P. (1993) 'Service firms' international entry-mode choice: a modified transaction-cost analysis approach', Journal of Marketing 57(3): 19-38.

Feichtinger, C. and Fink, G. (1998) 'The collective culture shock in transition countries: theoretical and empirical implications', Leadership and Organizational Development Journal 19(6): 302-324.
Finney, J.W., Mitchell, R.E., Cronkite, R.C. and Moos, R.H. (1984) 'Methodological issues in estimating main and interactive effects: examples from coping/social support and stress field', Journal of Health and Social Behavior 25(1): 85-98.

Friedrich, R.J. (1982) 'In defense of multiplicative terms in multiple regression equations', American Journal of Political Science 26(4): 797-833.

Gatignon, H. and Anderson, E. (1988) 'The multinational degree of control over foreign subsidiaries: an empirical test of a transaction cost explanation', Journal of Law, Economics, and Organization 4(2): 305-336.

Gavetti, G. and Levinthal, D. (2000) 'Looking forward and looking backward: cognitive and experiential search', Administrative Science Quarterly 45(1): 113-137.

Geringer, J.M. and Hebert, L. (1991) 'Measuring performance of international joint ventures', Journal of International Business Studies 22(2): 249-263.

Greenwood, R. and Hinings, J.R. (1993) 'Understanding strategic change: the contributions of archetypes', Academy of Management Journal 36(5): 1052-1081.

Hair, J.F., Black, B., Babin, B., Anderson, R. and Tatham, R.L. (2006) Multivariate Data Analysis, 6th edn, Prentice-Hall: Upper Saddle River.

Hargadon, A. and Fanelli, A. (2002) 'Action and possibility: reconciling dual perspectives of knowledge in organizations', Organization Science 13(3): 290-302.

Haunschild, P.R. and Sullivan, B.N. (2002) 'Learning from complexity: effects of prior accidents and incidents on airlines' learning', Administrative Science Quarterly 47(4): 609-643.

Hayward, M.L.A. (2002) 'When do firms learn from their acquisition experience? Evidence from 1990 to 1995', Strategic Management Journal 23(1): 21-39.

He, Z.L. and Wong, P.K. (2004) 'Exploration vs. exploitation: an empirical test of the ambidexterity hypothesis', Organization Science 15(4): 481-494.

Hedlund, G. and Kverneland, A. (1983) 'Are entry strategies for foreign markets changing? The Case of Swedish investment in Japan', reprinted in P.J. Buckley and P.N. Ghauri (eds.) (1993) The Internationalization of the Firm: A Reader, Academic Press Limited: London, pp: 106-123.

Helfat, C.E. (1994) 'Evolutionary trajectories in petroleum firm $\mathrm{R} \& \mathrm{D}^{\prime}$, Management Science 40(12): 1720-1747.

Hitt, M.A., Keats, B.W. and DeMarie, S.M. (1998) 'Navigating in the new competitive landscape: building strategic flexibility and competitive advantage in the 21 st century', Academy of Management Executive 12(4): 22-42.

Hofstede, G. (1980) Culture's Consequences: International Differences in Work-Related Values, Sage Publications: Beverly Hills.

Hofstede, G. and Bond, M.H. (1988) 'The Confucius connection: from cultural roots to economic growth', Organizational Dynamics 16(4): 5-21.

Holmqvist, M. (2004) 'Experiential learning processes of exploitation and exploration within and between organizations: an empirical study of product development', Organization Science 15(1): 70-81.

Hout, T., Porter, M.E. and Rudden, E. (1982) 'How global companies win out', Harvard Business Review 60(SeptemberOctober): 98-108.

Huff, A.S. (1990) 'Mapping strategic thought', in Huff, A.S. (ed.) Mapping Strategic Thought, Wiley: Chichester, pp. 11-49.

Hymer, S.H. (1975) The International Operations of National Firms: A Study of Direct Foreign Investment, MIT Press: Cambridge, MA

Jansen, J.J.P., Van den Bosch, F.A.J. and Volberda, H.W. (2006) 'Exploratory innovation, exploitative innovation, and performance: effects of organizational antecedents and environmental moderators', Management Science 52(11): 1661-1674.

Johanson, J. and Mattson, L.G. (1985) 'Marketing investments and market investments in industrial networks', International Journal of Research in Marketing 2(3): 185-195. 
Johanson, J. and Vahlne, J.-E. (1977) 'The internationalization process of the firm: a model of knowledge development and increasing foreign market commitments', Journal of International Business Studies 8(1): 23-32.

Johanson, J. and Vahlne, J.-E. (1990) 'The mechanism of internationalization', International Marketing Review 7(4): 11-24.

Johanson, J. and Wiedersheim-Paul, F. (1975) 'The internationalization of firms: four Swedish cases', Journal of Management Studies 12(3): 305-322.

Katila, R.A. and Ahuja, G. (2002) 'Something old, something new: a longitudinal study of search behavior and new product introduction', Academy of Management Journal 45(6): 1183-1194.

Knickerbocker, F.T. (1973) Oligopolistic Reaction and Multinational Enterprise, Harvard Business School Press: Boston, MA.

Kogut, B. and Singh, H. (1988) 'The effect of national culture on the choice of entry mode', Journal of International Business Studies 19(3): 411-432.

Lei, D., Hitt, M.A. and Bettis, R. (1996) 'Dynamic core competences through meta-learning and strategic context', Journal of Management 22(4): 549-569.

Levinthal, D.A. (1997) 'Adaptation on rugged landscapes', Management Science 43(7): 934-950.

Levinthal, D.A. and March, J.G. (1993) 'The myopia of learning', Strategic Management Journal 14(Winter Special Issue): 95-112.

Levitt, B. and March, J.G. (1988) 'Organizational learning', Annual Review of Sociology 14(1): 319-340.

Levitt, T. (1983) 'The globalization of markets', Harvard Business Review 61(3): 92-102.

$\mathrm{Li}$, J. (1995) 'Foreign entry and survival: effects of strategic choices on performance in international markets', Strategic Management Journal 16(5): 333-351.

Louis, M.R. and Sutton, R.I. (1991) 'Switching cognitive gears: from habits of mind to active thinking', Human Relations 44(1): 55-76.

Luthans, F., Stajkovic, A.D. and Ibrayeva, E. (2000) 'Environmental and psychological challenges facing entrepreneurial development in transitional economies', Journal of World Business 35(1): 95-110.

Makhija, M. and Stewart, A. (2002) 'The effect of national context on perceptions of risk: a comparison of planned versus free-market managers', Journal of International Business Studies 33(4): 737-756.

March, J.G. (1991) 'Exploration and exploitation in organizational learning', Organization Science 2(1): 71-87.

March, J.G., Sproull, L.S. and Tamuz, M. (1991) 'Learning from samples of one or fewer', Organization Science 2(1): 1-13.

Martin, X., Swaminathan, A. and Mitchell, W. (1998) 'Organizational evolution in the interorganizational environment: incentives and constraints on international expansion strategy', Administrative Science Quarterly 43(3): 566-601.

McGrath, G.R. (2001) 'Exploratory learning, innovative capacity, and managerial oversight', Academy of Management Journal 44(1): 118-131.

Meyer, K. (1998) Direct Investment in Economies in Transition, Edward Elgar: Cheltenham.

Meyer, K. (2001) 'Institutions, transaction costs, and entry mode choice in Eastern Europe', Journal of International Business Studies 32(2): 357-368.

Meyer, K.E. and Estrin, S. (2001) 'Brownfield entry in emerging markets', Journal of International Business Studies 32(3): 575-584.

Meyer, K.E. and Peng, M.W. (2005) 'Probing theoretically into Central and Eastern Europe: transactions, resources, and institutions', Journal of International Business Studies 36(6): 600-621.

Miller, D. and Chen, M.J. (1994) 'Sources and consequences of competitive inertia: a study of the US airline industry', Administrative Science Quarterly 39(1): 1-23.

Miller, D. and Chen, M.J. (1996) 'Nonconformity in competitive repertoires: a sociological view of markets', Social Forces 74(4): 1209-1234.
Murtha, T.P., Lenway, S.A. and Hart, J.A. (2001) Managing New Industry Creation, Global Knowledge Formation and Entrepreneurship in High Technology, Stanford University Press: Stanford.

Neter, J., Kutner, M.H., Nachtsheim, C.J. and Wasserman, W. (1996) Applied Linear Statistical Models, McGraw-Hill: Boston, MA

Nordström, K. (1991) The Internationalization Process of the Firm: Searching for New Patterns and Explanations, Stockholm School of Economics: Stockholm.

North, D.C. (1990) Institutions, Institutional Change, and Economic Performance, Cambridge University Press: Cambridge. Peng, M.W. and Heath, P.S. (1996) 'The growth of the firm in planned economies in transition: institutions, organizations, and strategic choice', Academy of Management Review 21(2): 492-528.

Penrose, E. (1959) The Theory of the Growth of the Firm, Oxford University Press: Oxford.

Root, F.R. (1987) Entry Strategies for International Markets, Heath: Lexington.

Ronen, S. and Shenkar, O. (1985) 'Clustering countries on attitudinal dimensions: a review and synthesis', Academy of Management Review 10(3): 435-454.

Rosenkopf, L. and Nerkar, A. (2001) 'Beyond local search: boundary-spanning, exploration, and impact in the optical disc industry', Strategic Management Journal 22(4): 287-306.

Rothaermel, F.T. and Deeds, D.L. (2004) 'Exploration and exploitation alliances in biotechnology: a system of new product development', Strategic Management Journal 25(3): 201-222.

Rugman, A.M. and Verbeke, A. (2004) 'A perspective on regional and global strategies of multinational enterprises', Journal of International Business Studies 35(1): 3-18.

Schneider, S.S. and De Meyer, A. (1991) 'Interpreting and responding to strategic issues: the impact of national culture', Strategic Management Journal 12(4): 307-320.

Shaver, J.M., Mitchell, W. and Yeung, B. (1997) 'The effect of own-firm and other-firm experience on foreign direct investment survival in the United States, 1987-1992', Strategic Management Journal 18(10): 811-824.

Shenkar, O. (2004) 'One more time: international business in a global economy', Journal of International Business Studies 35(2): 161-171.

Sidhu, J.S., Commandeur, H.R. and Volberda, H.W. (2007) 'The multifaceted nature of exploration and exploitation: value of supply, demand, and spatial search for innovation', Organization Science 18(1): 20-38.

Siggelkow, N. and Levinthal, D.A. (2003) 'Temporarily divide to conquer: centralized, decentralized, and reintegrated organizational approaches to exploration and adaptation', Organization Science 14(6): 650-669.

Stuart, T.E. and Podolny, J.M. (1996) 'Local search and the evolution of technological capabilities', Strategic Management Journal 17(Special Issue): 21-38.

Thomas, J.B., Watts Sussman, S. and Henderson, J.C. (2001) 'Understanding "strategic learning": linking organizational learning, knowledge management, and sensemaking', Organization Science 12(3): 331-345.

Uhlenbruck, K. (2004) 'Developing acquired foreign subsidiaries: the experience of MNEs in transition economies', Journal of International Business Studies 35(2): 109-123.

United Nations Conference on Trade Development (UNCTAD) (2005) World Investment Report 2005: Transnational Corporations and the Internationalization of $R \& D$, United Nations: New York/Geneva.

Vernon, R. (1966) 'International investment and international trade in the product cycle', Quarterly Journal of Economics 80(2): 190-207.

Walsh, J.P. (1995) 'Managerial and organizational cognition: notes from a trip down memory lane', Organization Science 6(3): $280-321$ 
Winter, S.G. and Szulanski, G. (2001) 'Replication as strategy', Organization Science 12(6): 730-743.

Wooster, R.B. (2006) 'US companies in transition economies: wealth effects from expansion between 1987 and 1999', Journal of International Business Studies 37(2): 179-195.

World Bank (1996) World Development Report: From Plan to Market, World Bank: Washington.

Yelle, L.E. (1979) 'The learning curve: historical review and comprehensive survey', Decision Sciences 10(2): 302-328.

Yip, G.S., Biscarri, J.G. and Monti, J.A. (2000) 'The role of the internationalization process in the performance of newly internationalizing firms', Journal of International Marketing 8(3): 10-35.

Zollo, M. and Winter, S.G. (2002) 'Deliberate learning and the evolution of dynamic capabilities', Organization Science 13(3): 339-351.

\section{About the authors}

Harry Barkema was Professor of Strategy and International Business at Tilburg University at the time of writing this article. He currently holds the DSM Distinguished Chair in Management of Innovation at the Rotterdam School of Management, and is a Professor of Management at the Department of Management at the London School of Economics. He is also the Director of the Innovation Cocreation Lab, focusing on developing new strategies and organisational forms for innovation.

Rian Drogendijk is Assistant Professor of International Management at Uppsala University. Her research interests include the effects of national culture and national cultural differences on international management, internationalisation processes of companies, and organisational learning in internationalising companies. 